owing to the extended position of one of the arms in each of the specimens shown. The publisher and printer are also to be congratulated on the excellent reproduction of the photographs.

The text is as good as the illustrations. As zoologist at the laboratory of the Marine Biological Association of the United Kingdom, Dr. Wilson knows the Plymouth fauna thoroughly, and confines his examples almost entirely to that area. Written in a smoothly flowing style, the book is full of interesting observations on the living animals, their movements, feeding habits, breeding and development, relationships with one another, and the chemical and physical conditions of their environment. Dr. Wilson also draws largely on recent work, such as the studies of Corbin and Steven on the migrations of the mackerel, Moore on the relation between food and shell colour in Nucella lapillus, Wells and Newell on the habits and lifehistory of Erenicola, and his own beautiful work on the settlement of polychæte larvæ and the postponement of their metamorphosis until the correct material for their tubes has been found by the larvæ. He refers also to recent work on echo-sounding for the determination of the noises made by marine animals, and to the under-water photography now being undertaken by Dr. H. G. Vevers.

There are two statements that I regret to see perpetuated : the left eye of the young plaice does not 'move' in the sense that the reader will infer from the account on pp. 22 and 163 ; and the alternation of an asexual and a sexual form (p. 171) is not an "alternation of generations" but of phases in one life-history.

The references to Chthamalus on pp. 26,50 and 68 are to Fig. 41 ; but this figure shows the wrong habitat for the barnacle. Should the reference be to Fig. 44 ?

There is an appendix of practical instructions, including useful hints on shore collecting, keeping an aquarium and photographing living marine animals. The book has been improved by its reduction to octavo size. It is very well printed and the price is reasonable.

N. B. EALES

\section{AMERICAN HYDNUMS}

\section{The Stipitate Hydnums of the Eastern United States}

By Prof. William Chambers Coker and Alma Holland Beers. Pp. viii + 211 (60 plates). (Chapel Hill, N.C. : University of North Carolina Press; London : Oxford University Press, 1951.) 40s. net.

DROF. W. C. COKER'S important contributions to the systematics of the higher fungi of North America are well known. His publications on the Hydnaceæ (Basidiomycetes) began in 1919, and the present work is a very convenient and welcome summary of the sixty non-resupinate species discovered in the eastern United States. They are placed in ten genera, which follow in the main Banker's classification (1901-13) and which are based on the macroscopic appearance of the fruit-body and the colour and marking of the spores. Twenty-three of these species occur also in Europe, and Hydnum fragile Fr. (1852) is given as a synonym of the new monotypic genus Bankera. Several of the species occur also in tropical and south-temperate countries. Indeed, in my experience, many of these apparently north-temperate species occur in conspecific or closely related form in the tropics; even the coniferous habitat of many does not seem obligatory, as in the case of Sarcodon (Hydnum) imbricatus, which Coker and Beers report as definitely associated with frondose woods in the eastern United States. Clearly, this book should be on the shelves of all mycologists, or libraries, concerned with the higher Basidiomycetes. The systematics of fungi are cosmopolitan, and this work is one of the indispensable stepping-stones to a world monograph of Hydnoid fungi.

The species are illustrated with characteristically good and well-reproduced photographs, mostly from living specimens, and there are clear line-drawings of spores and other microscopic details, as in Prof. Coker's previous monographs on Clavaria, Gasteromycetes and Boletus. Spore measurement would also appear precise, though it is not explained how spores, regular or irregular, are measurable to an accuracy of $0.1 \mu$. The specific descriptions are followed by critical notes on synonymy and related species.

The book bears, nevertheless, too much the stamp of compilation from separate papers, not only in the absence of critical summaries of such interesting matters as seasonal occurrence, geographical distribution, microchemical reaction, and variation in habitat, colour and size, but also in its plan. The usefulness of a systematic work, being primarily one of reference, is greatly enhanced by its usableness. It is not easy to find one's way about this book, small though it be, because the order is not apparent, the generic captions are ill-displayed, and indicative page-headings are lacking. To have always to consult the index does not make a book companionable. I have found that, in the uncertain state of knowledge of the natural affinities of Basidiomycetes, the alphabetical arrangement of genera, species and varieties is the most satisfactory : it is self-explanatory, selfindexing, and without disadvantage when, as in the present case, it is obvious from modern criteria that the genera do not form a natural family and the interrelations of the species, even if rightly placed in the same genus, are dubious. Again, for the comparison of descriptions, it is desirable to conform rigidly to the same order for the parts described and to italicize, as Fries did, the salient features of the species. In the case of the spores (for example, Plates 54-60), they should be orientated with respect to the apiculus, instead of the random presentation in the spore print. Distinctive type is also helpful in the indexing of synonyms along with legitimate names. Incidentally, the expression "threads of the flesh" for hyphæ is surely archaic.

According to the International Rules of Nomen. clature, Fries (1821) is the starting point for these fungi. The authors, however, use pre-Friesian names, commonly without reference to the Systema Mycologicum, and in several cases it is impossible to know, without consulting Fries, if the epithet is legitimate, for example, Bankera fuligineo-alba (Schmidt) and Hydnellum zonatum (Batsch). In my opinion such names are nomenclaturally incorrect because the epithets have no nomenclatural standing, unless as invalid. Thus, to write Hydnum L. or $H$. repandum $L$., as the authors have done, is contrary to the Rules and should be discontinued. A more serious contravention is the absence of any Latin diagnoses for the new genus and two new species described in the book. It is to be hoped that the authors will validate their new taxa in a mycological journal at the earliest opportunity.

E. J. H. CORNER 